\title{
Inundação e carga em coluna de absorção recheada
}

\author{
Flooding and loading in packed columns absorption \\ Inundación y carga en columna de absorción con relleno
}

Recebido: 26/02/2021 | Revisado: 04/03/2021 | Aceito: 08/03/2021 | Publicado: 16/03/2021

\author{
João Carlos Ferreira Lima \\ ORCID: https://orcid.org/0000-0003-0956-9300 \\ Universidade Federal da Bahia, Brasil \\ E-mail: joaocarlos.jcfl@hotmail.com \\ Jarlon Conceição da Costa \\ ORCID: https://orcid.org/0000-0002-0679-488X \\ Universidade Federal da Bahia, Brasil \\ E-mail: jharllon@hotmail.com \\ Silvana Mattedi \\ ORCID: https://orcid.org/0000-0003-4816-7494 \\ Universidade Federal da Bahia, Brasil \\ E-mail: Silvana@ufba.br \\ Luiz Mário Nelson de Góis \\ ORCID: https://orcid.org/0000-0001-8536-8936 \\ Universidade Salvador, Brasil \\ E-mail: Luiz.gois@unifacs.br
}

\begin{abstract}
Resumo
No presente trabalho é estudada a hidrodinâmica de uma torre de absorção com recheio de anéis de vidro através da determinação das faixas de inundação e de carga na operação da absorvedora. Na inundação a fase gasosa impede o escoamento da corrente líquida provocando o arraste pelo topo da coluna. No estudo são testadas várias combinações de vazões e determinados os pontos de carga e de inundação. Três regiões de operação são determinadas e o ponto crítico de operação, onde ocorre a estabilização da diferença de pressão na coluna, também é obtido.
\end{abstract}

Palavras-chave: Inundação; Carga; Coluna recheada; Absorção.

\begin{abstract}
In the present work, the hydrodynamics of an absorption tower with filling of glass rings is studied through the determination of the flooding and loading ranges in the absorber operation. In the flooding, the gas phase prevents the flow of the liquid stream, causing it to drag along the top of the column. In the study, various combinations of flow rates are tested and the loading and flooding points. Three operating regions are determined and the critical point of operation, where the pressure difference in the column stabilizes is also obtained.
\end{abstract}

Keywords: Flooding; Loading; Packed columns; Absorption.

\section{Resumen}

En el presente trabajo se estudia la hidrodinámica de una torre de absorción con relleno de anillos de vidrio mediante la determinación de los rangos de inundación y carga en la operación del absorbedor. En la inundación, la fase gaseosa impide el flujo de la corriente líquida, lo que hace que se arrastre a lo largo de la parte superior de la columna. En el estudio, se prueban varias combinaciones de caudales y se determinan los puntos de carga e inundación. Se determinan tres regiones operativas y también se obtiene el punto crítico de operación, donde se estabiliza la diferencia de presión en la columna.

Palabras clave: Inundación; Carga; Columnas empaquetadas; Absorción.

\section{Introdução}

A absorção é uma operação em que uma mistura gasosa é contatada com um líquido com o objetivo de separar preferencialmente um ou mais componentes A operação requer então a transferência de massa do soluto da corrente gasosa para a corrente líquida. Quando a transferência ocorre na direção oposta, ou seja, da fase líquida para a fase gasosa, é chamada de dessorção ou "stripping" (Treybal, 1980). A operação ocorre em colunas conhecida como torres de recheio ou colunas recheadas, onde vários fatores influenciam na taxa de transferência de massa que acontece entre as duas fases da operação. Estes fatores vão desde o tipo de recheio utilizado, dados de geometria, como diâmetro, comprimento, etc., até parâmetros operacionais como, 
vazões, temperatura, concentrações, etc.

Na absorção há sempre a presença de duas fases, a contínua e a dispersa, onde na forma de gotas, o soluto presente na fase contínua, é transportado para a fase dispersa através do contato contra-corrente. Assim, dados como área de contato interfacial, coeficiente de transferência de massa, fração de holdup, diâmetro de gota, entre outros, tornam-se de fundamental importância no funcionamento dos absorvedores por estarem diretamente ligados ao transporte de massa que ocorre no interior das torres.

Sendo assim, entende-se como o comportamento hidrodinâmico, ou a hidrodinâmica das absorvedoras, o estudo das variações e das influências dos parâmetros de operação, com o objetivo da busca de melhor forma de operação das torres. O que pode observado nos trabalhos de Costa; Góis e Mattedi, (2020) e no de Bernardes e Góis (2020), onde expõem a relevância sobre estudo hidrodinâmico em suas pesquisas, envolvendo colunas de extração pulsada e recheada. Nessa linha, a determinação das faixas de inundação, aparece como de grande importância nos processos de separação em contracorrente, já que ocorre o impedimento do fluxo de uma das fases no escoamento. No caso das absorvedoras, ocorre o impedimento da corrente de líquido descer na coluna, enquanto na carga o fluxo de ar é impedido de ascender na coluna. Ou seja, determinadas as faixas de operação onde ocorrem estes dois fenômenos, a operação da coluna ficará bem mais facilitada.

Portanto, no presente trabalho é apresentado um estudo da hidrodinâmica de uma absorvedora com recheio de anéis de vidro, com $7 \mathrm{~cm}$ de diâmetro interno e 1m de altura com o objetivo da determinação das faixas de inundação e de carga da coluna. As duas faixas são obtidas através de dados de variação da queda de pressão e das vazões das duas correntes que são alimentadas na absorvedora.

\subsection{Análise da literatura}

Vários trabalhos publicados na literatura têm dedicado atenção ao estudo da operação das absorvedoras. Os estudos geralmente tratam de dados relacionados com características dos recheios, a transferência de massa, dados de projetos ou da influência de parâmetros na operação das torres.

Dentre os parâmetros operacionais existentes a queda de pressão, segundo Heyouni, et al.(2002) pode ser considerado como o parâmetro mais importante no critério de configuração para uma torre de recheio, já que quantifica a dispersão das fases e é sendo decisivo na eficiência da operação. Os trabalhos realizados por Darake, et al., (2014); Flagiello, et al., (2019b), (2018a), (2018b); Iliuta e Larachi, (2019) e Schultes, et al., (2018) expõem sobre essa importância do estudo da queda de pressão em colunas de absorção. Sua dependência se resume em três fatores: a velocidade das fases líquida e gasosa, do tipo do fluído e do tipo de recheio envolvido. Uma outra justificativa, segundo estes autores, é a de que a pressão no topo da coluna ter que ser sempre menor que na base, devido a ação da força gravitacional se comportar de forma descendente. E aí, como o escoamento descendente do líquido ocupa os mesmos canais que o escoamento ascendente de gás ou líquido, a queda de pressão é sempre uma função das duas vazões.

Segundo Caldas e Lacerda (2003) vários são os modelos existentes na literatura que podem ser aplicados na avaliação da perda de carga $(\Delta \mathrm{P} / \mathrm{z})$, nas colunas de recheio. Segundo Caldas e Lacerda (2003) nestes modelos são geradas as Curvas Gerais de Queda Pressão (CGQP), onde a queda de pressão geralmente é relacionada com a vazão da fase gasosa na coluna. Os trabalhos geralmente tratam de colunas com leitos secos, onde somente a fase gasosa está presente, e com leitos molhados, onde as duas fases, líquida e gasosa estão presentes. No caso dos recheios randômicos, segundo este autor destacam-se como principais modelos para CGQP o de Ergun (1952) e o de Treybal (1980), somente para colunas com leitos secos. Já para as colunas com leitos molhados, ou com as duas fases presentes na operação, Caldas e Lacerda (2003) relaciona como principais os métodos de Leva (1953), Niranjan (1983), Billet e Mackowiak, (1984), Graff (1985) e o de Prahl (1970). Cada modelo citado por Caldas e Lacerda (2003), entretanto, apresentam condições específicas, como tipo de recheio, faixas de vazão etc., para a sua utilização. 
Já segundo Bianchini (2018) no processo da absorção haverá sempre uma das fases na de gotas, chamada de fase dispersa, e a outra denominada fase contínua, com intuído de aumentar a superfície de contato entre fases favorecendo assim o fluxo interfacial dos componentes. As duas fases normalmente se contatam em contracorrente e com velocidades variáveis no percurso da coluna. Neste contato surgem então outros parâmetros, como o holdup, e os pontos de carga e de inundação (flooding), que também irão influenciar fortemente na operação das torres. O holdup, segundo Bianchini (2018), caracteriza a fração retida da fase dispersa pela fase contínua no contato entre as fases, enquanto que a inundação representa o impedimento de uma das fases percorrer todo o comprimento da coluna. Nesta linha Liu (2014) inclusive realizou um estudo para desenvolvimento de um novo modelo de correlação para a determinação da velocidade de inundação em torres que são utilizadas nas indústrias química de refino de petróleo. Sendo que neste último trabalho, os autores apresentam somente uma breve discussão sobre a capacidade que uma coluna inundada tem de interromper uma linha de produção, e afetar a operação normal de todo um sistema de produção, sem, no entanto, apresentar modelos ou dados que determine as regiões de inundação das absorvedoras.

Segundo Bianchini (2018), a avaliação da faixa de inundação e de carga pode ser obtida através de gráficos logarítmicos onde são relacionados a perda de carga $(\Delta \mathrm{P} / \mathrm{Z})$ com a vazão de gás $\left(\mathrm{U}_{\mathrm{ar}}\right)$. Nestes gráficos são geradas as linhas de operação com leito seco, ou sem a presença de líquido, e com leito molhado com a presença de líquido e gás simultaneamente. Um exemplo destas linhas de operação é mostrado através do gráfico da Figura 1, onde três retas são traçadas utilizando-se o leito molhado (linhas $\mathrm{L}_{1}$ e $\mathrm{L}_{2}$ ) e o leito seco (linha $\mathrm{L}_{0}$ ).

Figura 1: Gráfico referente a determinação dos pontos de carga e de inundação em colunas de recheio.

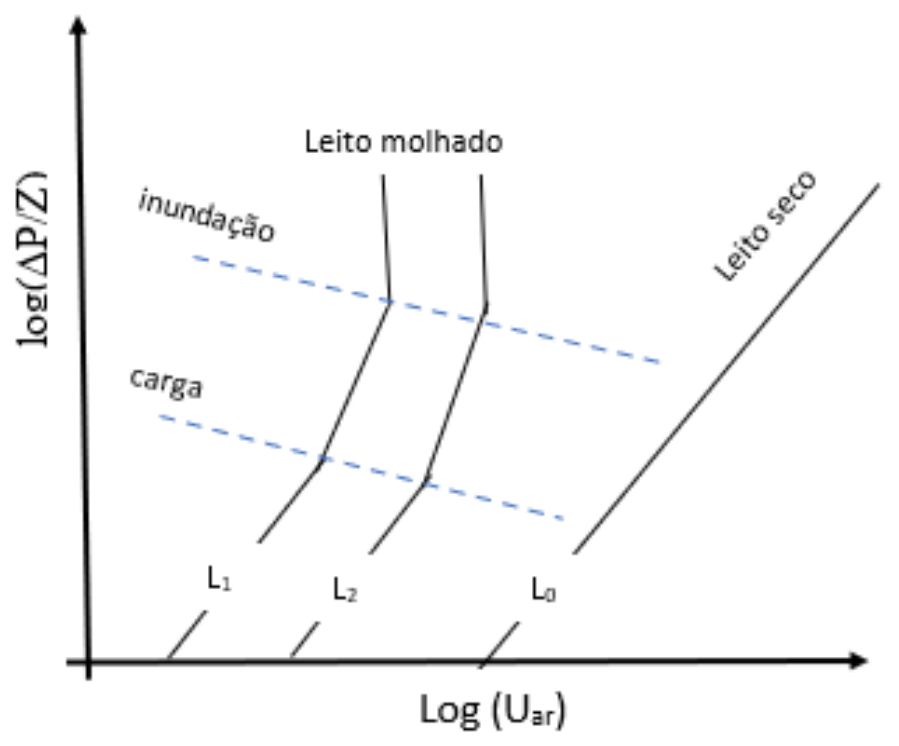

Fonte: Bianchini (2018)

Analisando-se as linhas apresentadas no gráfico da Figura 1, observa-se primeiramente que a baixas vazões de gás as três linhas apresentam uma mesma inclinação, tanto para leito seco como para leito molhado. Porém, a partir de determinadas de vazão de gás, as com leito molhado sofrem mudanças nas suas inclinações, provocando um distanciamento da linha com leito seco.

Segundo Nobrega (2007) as duas mudanças no comportamento das curvas da Figura 1 caracterizam os pontos de carga (loading point) e o de inundação (flooding point) que ocorrem na coluna, respectivamente. Ou seja, o ponto de carga é alcançado quando o aumento da velocidade do gás faz com que a inclinação da curva varie aumentando rapidamente a perda de carga. 
Segundo esses autores, a partir desse ponto, normalmente observa-se a presença de um gotejamento contínuo de líquido na coluna, indicando que o gás começa a impedir o escoamento do líquido que, por sua vez, vai se acumulando ao longo na coluna. Com vazões e quedas de pressão ainda mais elevadas, conforme observado na Figura 1, acontece a segunda mudança na inclinação da linha de operação indicando que o ponto de inundação (flooding point) foi alcançado. Segundo Nobrega (2007) ponto de inundação caracteriza também o início do arraste da fase líquida pela fase gasosa e geralmente é percebido visualmente pela formação de espuma na parte superior da coluna.

Guilherm, et al. (2016) também utilizaram os modelos de gráficos da Figura 1 para a determinação dos pontos de carga e inundação na absorção do tolueno com óleo lubrificante em uma torre com recheio de anéis de Raschig. O gráfico construído por estes autores é mostrado na Figura 2, onde claramente observa-se a indicação dos pontos de carga e de inundação.

Figura 2: Determinação do ponto de carga e de inundação.

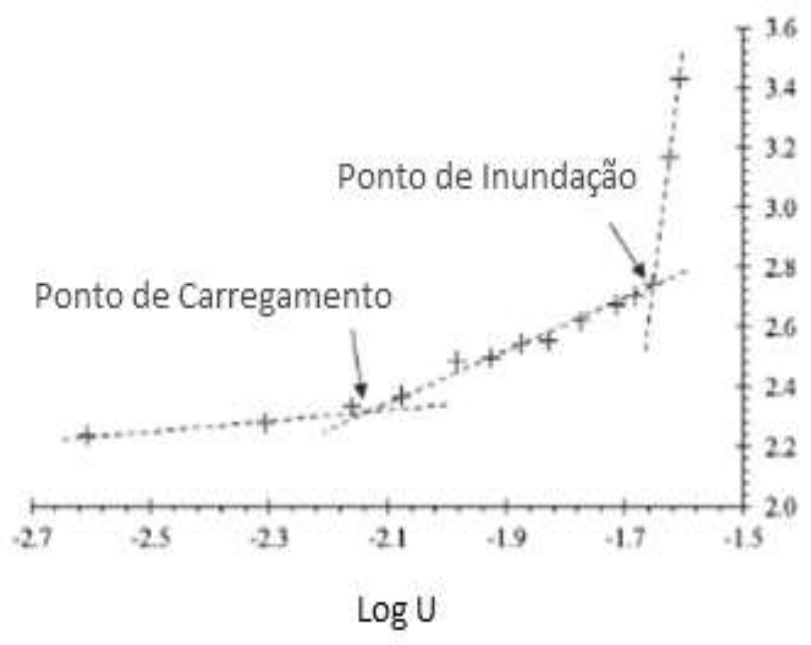

Fonte: Guillerm, et al., (2016)

Segundo Guilherm, et al., (2016) são identificadas três faixas de operação mostradas no gráfico da Figura 2, como três regimes hidrodinâmicos distintos de operação da coluna. O regime 1, abaixo do ponto de carga, caracterizado por não haver interações perceptíveis entre o gás e o líquido na coluna. O regime 2 (zona de carga), entre o ponto de carga e o ponto de inundação, onde acontece o acúmulo de líquido que ocorre nos vazios existentes no recheio. O regime 3 (zona de inundação), acima do ponto de inundação, onde o acúmulo de líquido no recheio é mais intenso provocando o arraste do líquido. Desta forma, percebe-se que identificados os três regimes de operação, pode-se obter uma maior eficiência no processo de transferência de massa através de ajuste nas duas vazões de alimentação da torre.

Sendo assim, diante dos trabalhos encontrados na literatura, o presente trabalho apresenta um estudo referente a determinação dos pontos de carga e de inundação em uma coluna de vidro com recheios randômicos de anéis de vidro. São determinadas as melhores faixas de operação da coluna e também a curva de queda de pressão com a razão entre as duas cargas. Nesta curva se obtém o ponto crítico, de onde se inicia a faixa de faixa de estabilidade da queda de pressão na coluna.

\section{Metodologia}

A escolha dos métodos e a busca por conhecimento sobre eles, norteiam de forma fidedigna e fundamentada toda uma pesquisa, procurando de maneira coesa a elaboração do trabalho científico. Portanto, essa investigação teve uma preocupação 
em ser conduzida através de uma pesquisa exploratória, dentro de uma abordagem quali-quantitativa, uma vez que se utilizou de coleta de dados por meio do uso de medições de grandezas, bem como envolveu interpretações da fenomenologia sistêmicas e das respostas obtidas (Cajueiro 2013; Pereira, et al 2018; Koche 2011).

Dessa forma, foram realizados testes experimentais conduzidos em uma coluna de absorção a nível de bancada laboratorial, de acrílico, com diâmetro de 0,07m e comprimento de 1,0m, com recheio de anéis de vidro com 0,0095 de comprimento e $0,008 \mathrm{~m}$ de diâmetro, totalizando uma altura total de recheio $0,79 \mathrm{~m}$. Na Figura 3 é mostrada uma fotografia da coluna utilizada.

Figura 3: Fotografia da coluna utilizada nos experimentos.

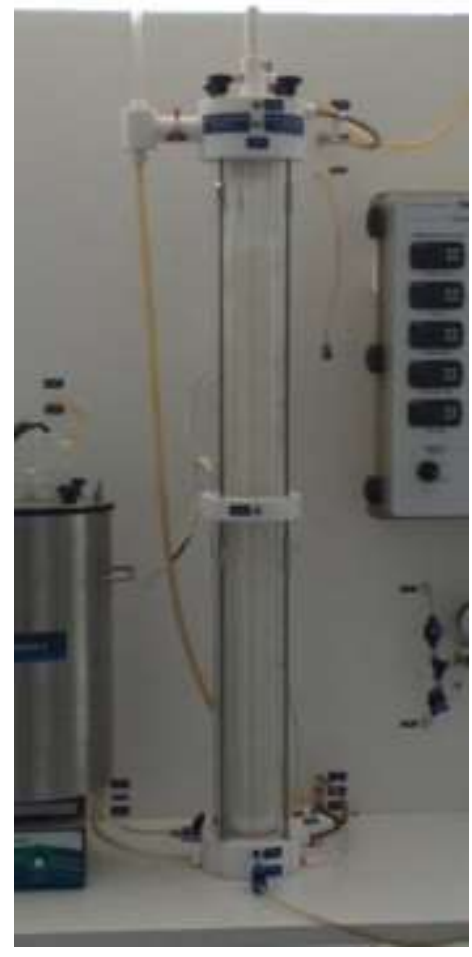

Fonte: Autores.

Nos testes as alimentações da coluna eram feitas pela base (fase gasosa) e pelo topo (fase líquida), sendo ambas controladas por rotâmetros. Já a queda de pressão era obtida através de um manômetro em U instalado nos dois extremos da torre. 
Figura 4: A instalação experimental.

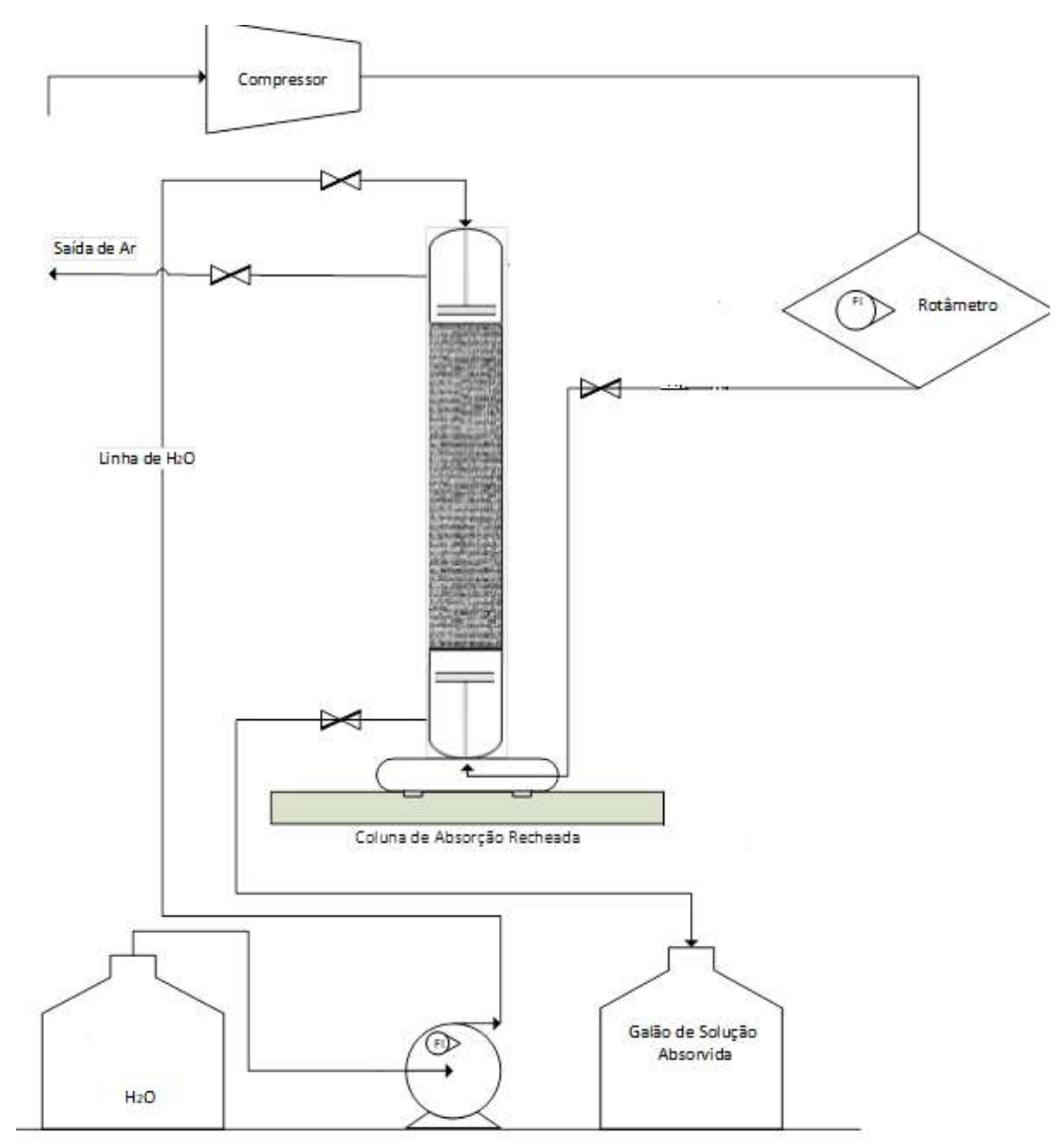

Fonte: Autores.

Foram realizados dois tipos de testes na presente pesquisa, os testes a seco e os testes molhados. Nos testes a seco somente a fase gasosa era introduzida pela base da coluna, enquanto que nos testes molhados as duas fases eram alimentadas, a gasosa (ar atmosférico) pela base e a fase líquida (água pura) pelo topo. Em ambos os testes as vazões de alimentação eram medidas através dos dois rotâmetros e feitas tomadas dos dados de diferença de pressão (sistema e pressão atmosférica), foram tomados em mm/ $\mathrm{H}_{2} \mathrm{O}$ através do manômetro em $\mathrm{U}$ (manômetro de coluna d'água) instalado ao sistema, após o regime estacionário ser atingido, onde todas as coletas foram feitas em triplicata de forma visual na régua milimétrica do manômetro. As vazões de ar variaram entre 0,2 e $15 \mathrm{~L} / \mathrm{min}$, enquanto que as de água entre 0,72 e 1,41 L/min. Os testes a seco totalizaram 19 experimentos enquanto que nos testes molhados foram 40 experimentos, já que para cada vazão de gás eram testadas as 5 vazões de líquido. Deve-se salientar que testes com algumas combinações de vazão não foram realizados devido a ter-se atingido a inundação da coluna. O fenômeno da inundação era visível já que ocorria um borbulhamento na parte superior da coluna causado devido a retenção do líquido pela fase gasosa.

\section{Resultados e Discussão}

Os resultados obtidos para os testes secos e os testes molhados são apresentados através das tabelas 1 e 2 mostradas a seguir. Em ambas as tabelas são ilustrados os valores das vazões e das respectivas quedas de pressão que foram medidas, sendo que nos testes molhados são descritos também as vazões de líquido utilizadas nos testes. Em seguida são mostrados os gráficos onde são identificados os comportamentos e os fenômenos observados nos experimentos. Nos gráficos geralmente são relacionadas as vazões com as quedas de pressão sendo identificados principalmente os pontos de carga e os de inundação. 
Tabela 1: Resultados obtidos com os testes secos.

\begin{tabular}{cccc}
\hline $\begin{array}{c}\mathbf{G} \text { ar } \\
(\mathbf{L} / \mathbf{m i n})\end{array}$ & $\begin{array}{c}\Delta \mathbf{P} / \mathbf{Z} \\
(\mathbf{P a} / \mathbf{m})\end{array}$ & $\begin{array}{c}\mathbf{G} \text { ar } \\
(\mathbf{L} / \mathbf{m i n})\end{array}$ & $\begin{array}{c}\Delta \mathbf{P} / \mathbf{Z} \\
(\mathbf{P a} / \mathbf{m})\end{array}$ \\
\hline \hline 0,2 & 19,6 & 7 & 595,7 \\
6 & 44,1 & 8 & 663,9 \\
1,2 & 117,9 & 9 & 704,3 \\
1,8 & 192,4 & 10 & 775,6 \\
2,5 & 260,6 & 11 & 837,7 \\
3 & 294,7 & 12 & 881,1 \\
3,6 & 328,9 & 13 & 912,1 \\
4 & 353,7 & 14 & 971,1 \\
5 & 465,4 & 15 & 1039,3 \\
6 & 539,8 & & \\
\hline
\end{tabular}

Fonte: Autores.

Nos testes molhados (Tabela 2) foram coletados valores de queda de pressão para 5 vazões de água distintas para cada vazão de ar utilizada. As vazões de ar variaram entre 1,2 até 6,0 L/min enquanto que as de água entre 0,72 e 1,41L/min. Em destaque na Tabela 2 também é mostrada em destaque as vazões onde foram identificados os fenômenos de carga (loading) e da inundação (flooding) ocorreram. Além destes estão representados por "Inundação" os pontos em que visivelmente se observava a inundação da coluna.

Tabela 2: Resultados experimentais de Queda de Pressão obtidos com os testes molhados.

\begin{tabular}{|c|c|c|c|c|c|}
\hline $\begin{array}{c}\mathbf{G}_{\text {ar }} \\
(\mathbf{L} / \mathbf{m i n})\end{array}$ & $\begin{array}{l}\mathbf{G}_{\text {água }} \\
\text { (L/min) }\end{array}$ & $\begin{array}{c}\Delta \mathbf{P} / \mathbf{Z} \\
(\mathbf{P a} / \mathbf{m})\end{array}$ & $\begin{array}{c}\mathbf{G}_{\text {ar }} \\
(\mathbf{L} / \mathbf{m i n})\end{array}$ & $\begin{array}{c}\mathbf{G}_{\text {água }} \\
(\mathbf{L} / \mathbf{m i n})\end{array}$ & $\begin{array}{c}\Delta \mathbf{P} / \mathbf{Z} \\
(\mathbf{P a} / \mathbf{m})\end{array}$ \\
\hline \multirow{5}{*}{1,2} & (0,72 & 2335,79 & \multirow{5}{*}{3,6} & (0,72 & 663,94 \\
\hline & 0,86 & 297,84 & & 0,86 & 595,68 \\
\hline & 1,13 & 521,22 & & 1,13 & 980,39 \\
\hline & 1,27 & 304,05 & & 1,27 & 918,34 \\
\hline & 1,41 & 459,17 & & 1,41 & 769,42 \\
\hline \multirow{5}{*}{1,8} & 0,72 & 297,84 & \multirow{5}{*}{4,0} & 0,72 & 843,88 \\
\hline & 0,86 & 335,07 & & 0,86 & 831,47 \\
\hline & 1,13 & 595,68 & & 1,13 & 1154,13 \\
\hline & 1,27 & 359,89 & & 1,27 & 1203,77 \\
\hline & 1,41 & 515,02 & & 1,41 & 806,65 \\
\hline \multirow{5}{*}{2,5} & 0,72 & 335,07 & \multirow{5}{*}{5,0} & 0,72 & 1042,4 \\
\hline & 0,86 & 397,12 & & 0,86 & Inundação \\
\hline & 1,13 & 694,96 & & 1,13 & 1526,4 \\
\hline & 1,27 & 446,76 & & 1,27 & Inundação \\
\hline & 1,41 & 558,45 & & 1,41 & 1141,7 \\
\hline \multirow{5}{*}{3,0} & 0,72 & 558,45 & \multirow{5}{*}{6,0} & 0,72 & 1265,8 \\
\hline & 0,86 & 508,81 & & 0,86 & Inundação \\
\hline & 1,13 & 831,47 & & 1,13 & Inundação \\
\hline & 1,27 & 744,60 & & 1,27 & Inundação \\
\hline & 1,41 & 620,50 & & 1,41 & Inundação \\
\hline
\end{tabular}

Fonte: Autores.

Na Figura 5 é mostrado um gráfico onde são relacionados os dados apresentados na Tabela 2. Ou seja, os valores da queda de pressão em função da vazão de ar para diferentes valores de vazão de água. Deve-se salientar também que os valores 
máximos de queda de pressão utilizados foram os em que era atingido o ponto de inundação da coluna, já que após atingida este ponto a operação da coluna torna-se ineficiente.

Figura 5: Queda de Pressão versus vazão de ar para diferentes valores de vazões de água.

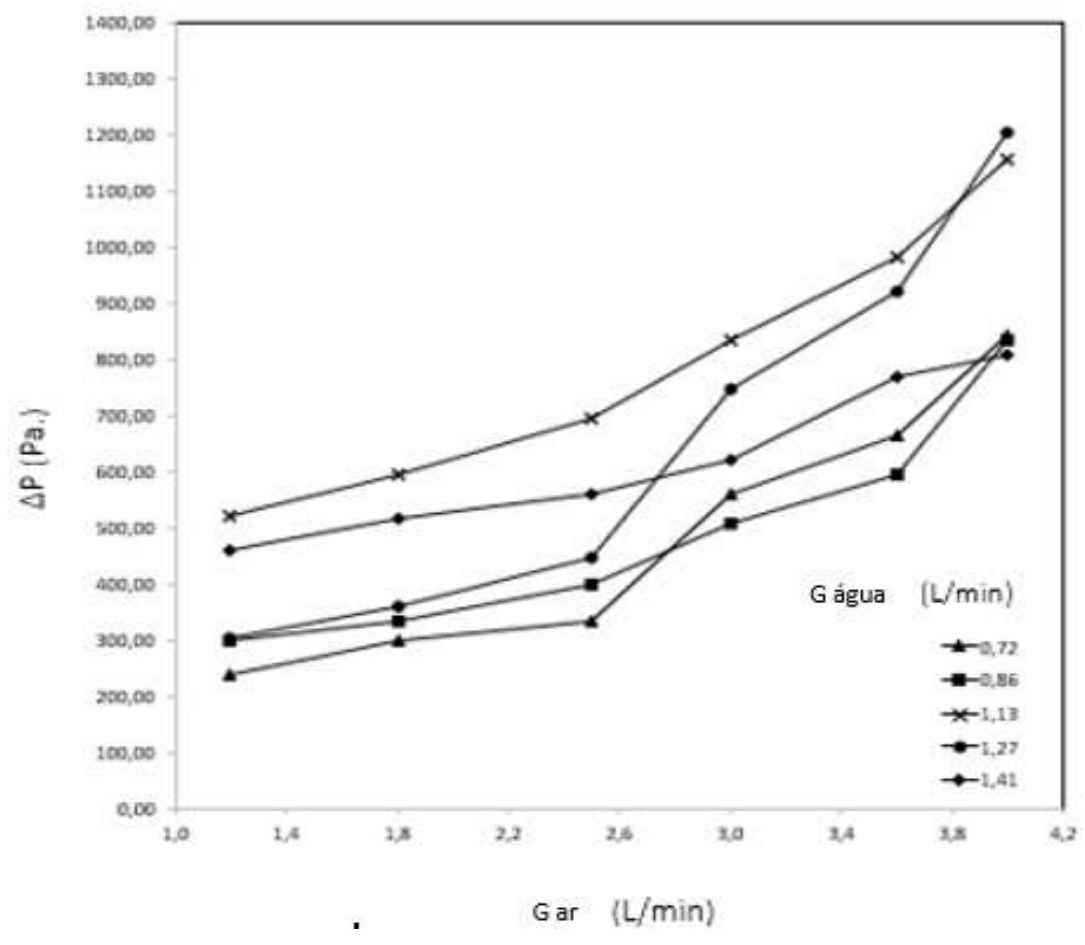

Fonte: Autores.

No gráfico observa-se primeiramente que em todas as curvas acontece um crescimento da queda de pressão com a vazão de ar. Isso é justificado tendo em vista que como a coluna recebe um maior volume de gás na sua alimentação, mais difícil será o caminho desse gás e, consequentemente maior deve ser a queda de pressão no seu interior. Este fenômeno é ainda mais acentuado com o aumento da vazão de água, como pode ser observado no gráfico. Ou seja, vazões de água mais elevadas irão dificultar ainda mais a passagem da corrente gasosa pela coluna. Daí, conforme mostrado na figura, em geral as curvas com vazões de água mais elevadas mostraram-se com valores de queda de pressão maiores que as com baixas vazões.

O gráfico da Figura 6 mostra a relação entre os valores da queda de pressão, $\Delta \mathrm{P}$, e a razão entre as vazões das duas fases, líquida e gasosa, $\mathrm{G}_{\text {águal }} \mathrm{G}_{\mathrm{ar}}$. 
Figura 6: Variação da queda de Pressão com a razão entre as vazões, $\mathrm{G}_{\text {águal }} \mathrm{G}_{\mathrm{ar}}$.

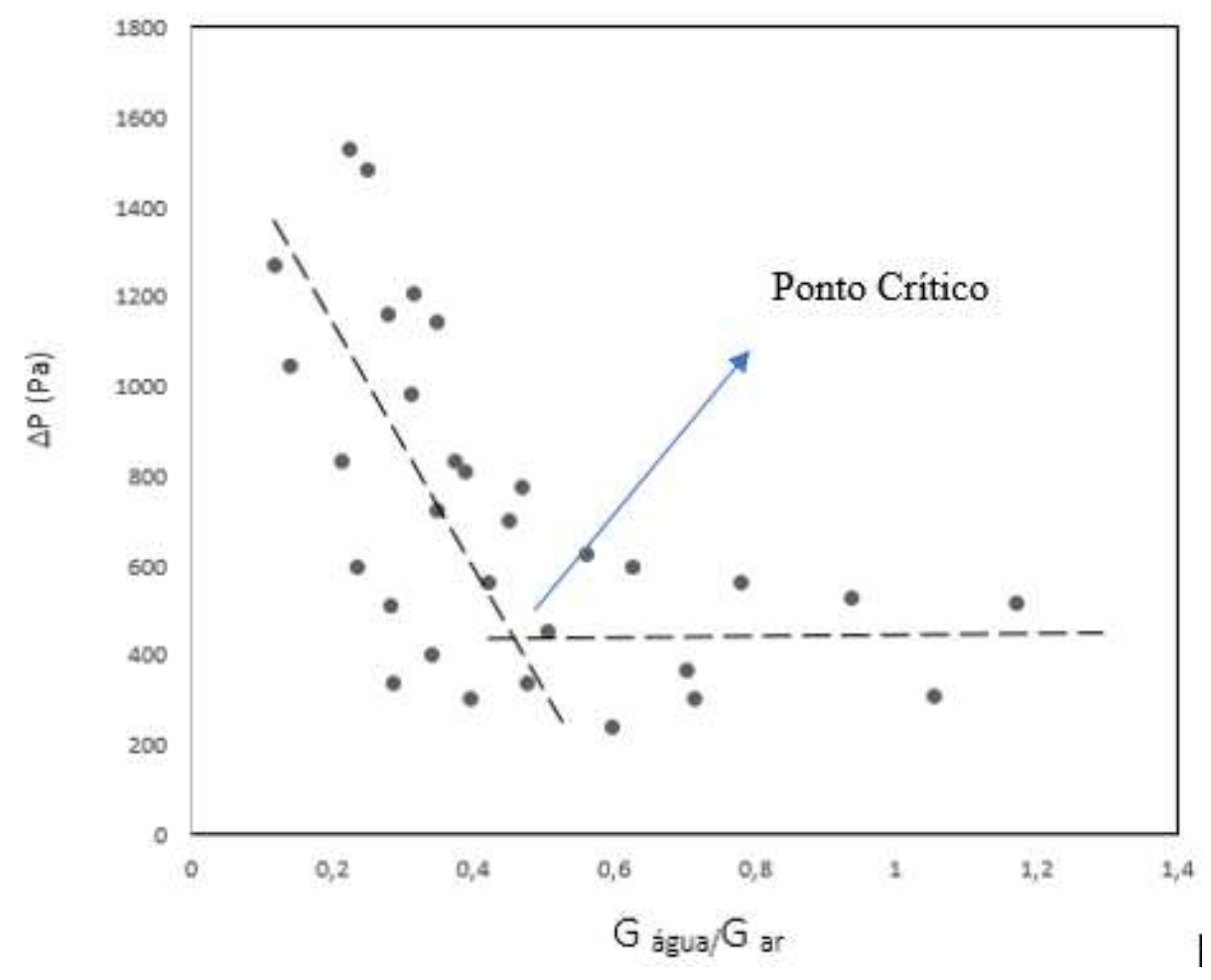

Fonte: Autores.

De acordo com o gráfico da Figura 6 observa-se primeiramente uma região que se aproxima do comportamento de uma reta descendente e, posteriormente, uma outra reta só que paralela ao eixo da abcissa. Ou seja, verifica-se que a queda de pressão decresce com o aumento da razão entre as fases até ser atingido um ponto em que o valor de $\Delta \mathrm{P}$ permanece constante. $\mathrm{O}$ ponto obtido do cruzamento das duas retas pode ser chamado de "ponto crítico", ou seja, o ponto cujo valor de $\mathrm{G}_{\text {água }} / \mathrm{G}_{\text {ar }}$ indica o início da faixa de estabilidade da queda de pressão na coluna. É importante a determinação desse ponto já que com a queda de pressão constante, um maior contato entre as duas fases na coluna é obtido, o que deve favorecer a transferência de massa no processo da absorção.

\subsection{As vazões de carga e de inundação}

Um outro estudo realizado no presente trabalho diz respeito a identificação das faixas de carga (loading) e de inundação (flooding) da coluna. Como já foi descrito anteriormente estas faixas são de grande importância na operação das absorvedoras já que o ponto de carga é justamente quando a corrente gasosa inicia o processo de impedir a passagem da corrente líquida. Enquanto que, segundo Guilherm, et al., (2016), é a partir do ponto de inundação que se inicia o processo de arraste do líquido pelo gás.

No presente trabalho os pontos de carga e de inundação foram também identificados através do modelo de Bianchini (2018), onde são utilizadas as mudanças de inclinação das linhas de operação formadas nos gráficos $\log (\Delta \mathrm{P} / \mathrm{Z}) \mathrm{versus} \log (\mathrm{U}$ ar $)$, mostrado na Figura 1.

Sendo assim, foram construídos os gráficos com as linhas de operação para leito seco e leito molhado para as cinco vazões de líquido utilizadas, seguindo o modelo proposto por Bianchini (2018) e identificados os pontos de carga e de inundação obtidos para cada teste com leito molhado realizado. As Figuras 7 a 11 mostram as linhas de operação e os pontos de carga e inundação obtidos dos experimentos. 
Research, Society and Development, v. 10, n. 3, e29410312369, 2021

(CC BY 4.0) | ISSN 2525-3409 | DOI: http://dx.doi.org/10.33448/rsd-v10i3.12369

Figura 7: Variação da queda de pressão com fluxo de $\operatorname{ar}$ molar $\left(G_{\text {água }}=0,72 \mathrm{~L} / \mathrm{min}\right)$.

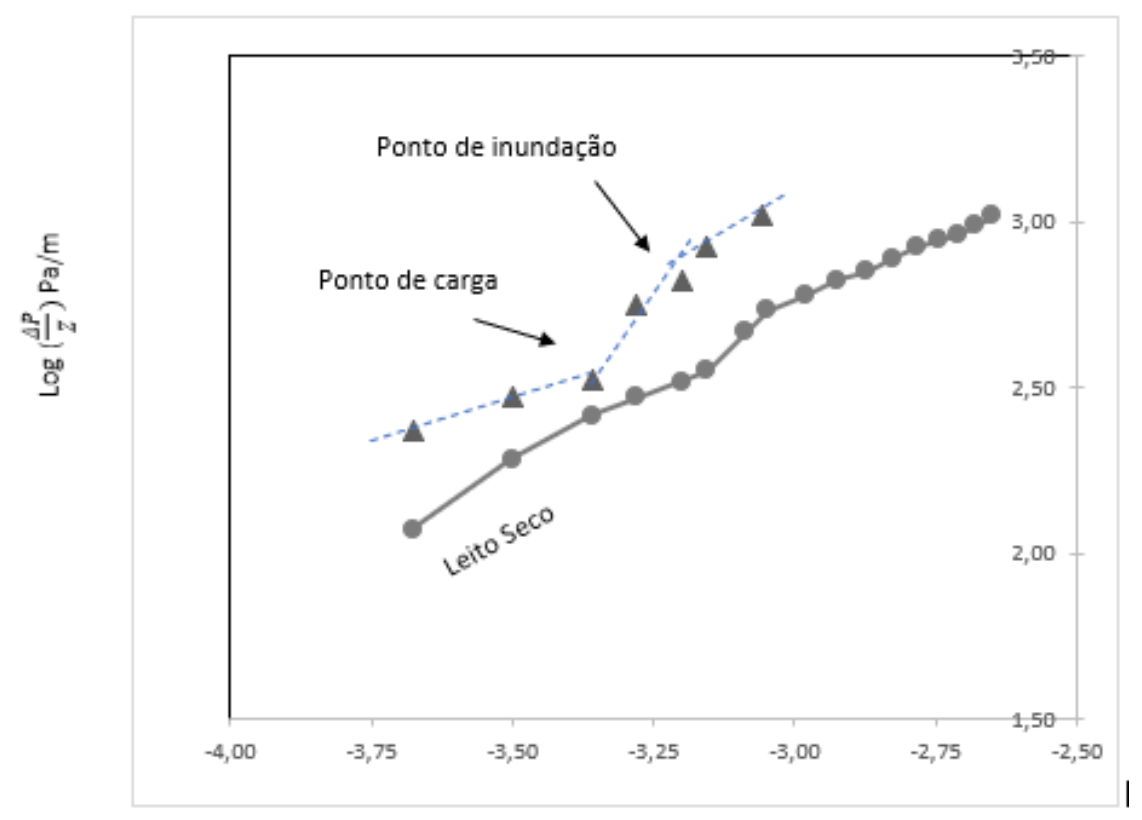

$\log ($ Uar $)\left(\mathrm{kmol} / \mathrm{m}^{2} \mathrm{~s}\right)$

Fonte: Autores.

Figura 8: Variação da queda de pressão com fluxo de $\operatorname{ar}$ molar $\left(G_{\text {água }}=0,86 \mathrm{~L} / \mathrm{min}\right)$.

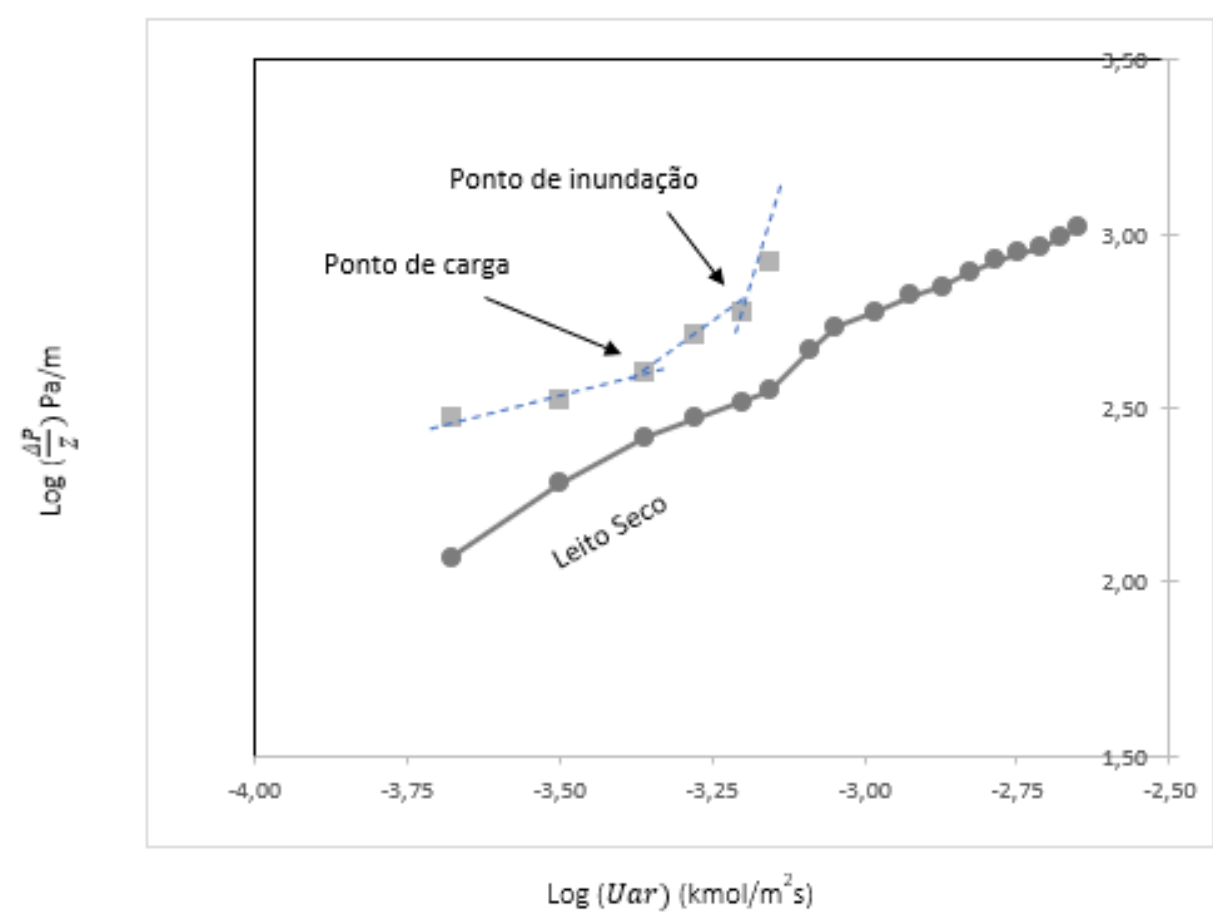

Fonte: Autores. 
Research, Society and Development, v. 10, n. 3, e29410312369, 2021

(CC BY 4.0) | ISSN 2525-3409 | DOI: http://dx.doi.org/10.33448/rsd-v10i3.12369

Figura 9: Variação da queda de pressão com fluxo de $\operatorname{ar}$ molar $\left(\mathrm{G}_{\text {água }}=1,13 \mathrm{~L} / \mathrm{min}\right)$.

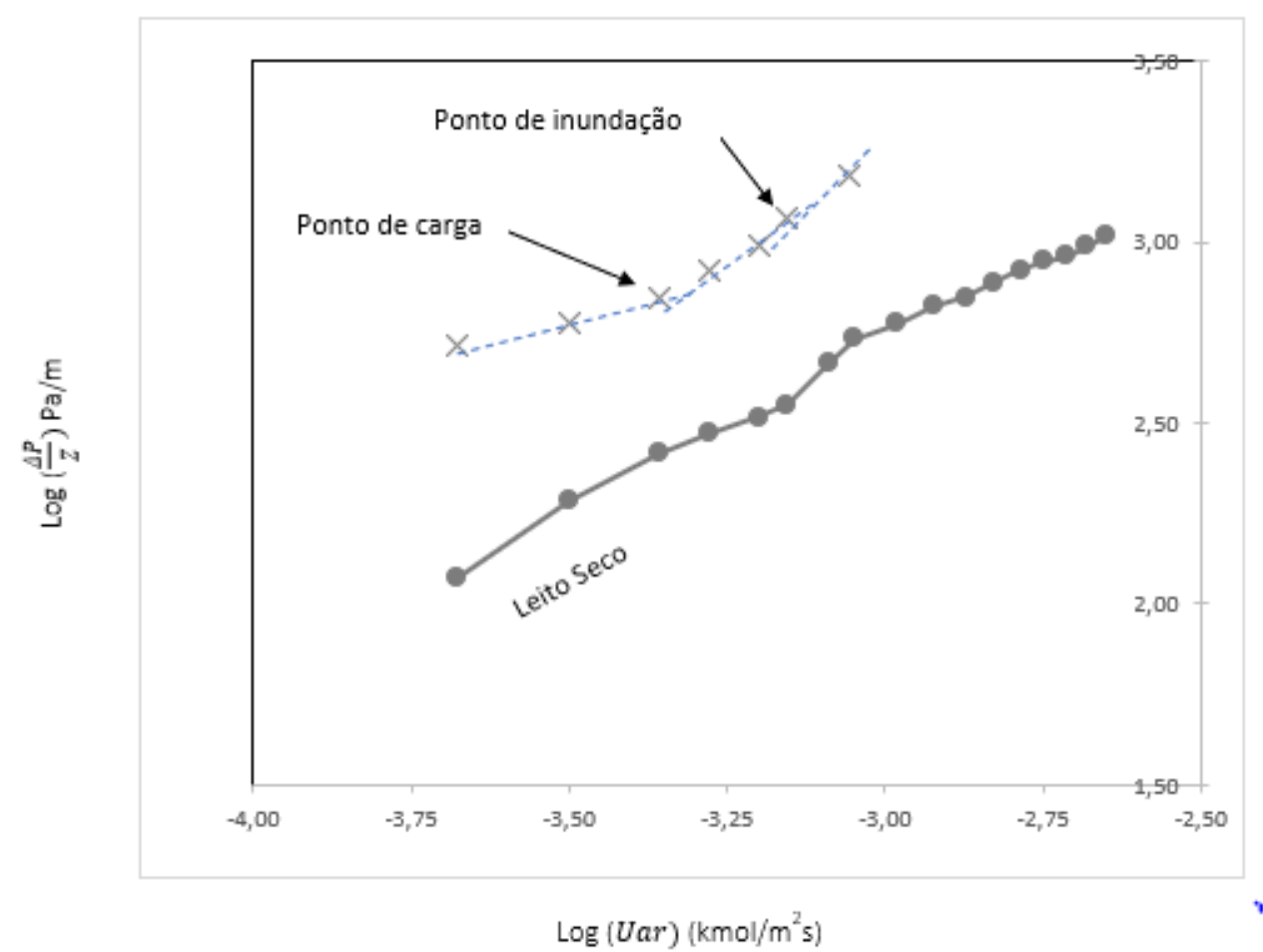

Fonte: Autores.

Figura 10: Variação da queda de pressão com fluxo de $\operatorname{ar} \operatorname{molar}\left(\mathrm{G}_{\text {agua }}=1,27 \mathrm{~L} / \mathrm{min}\right)$.

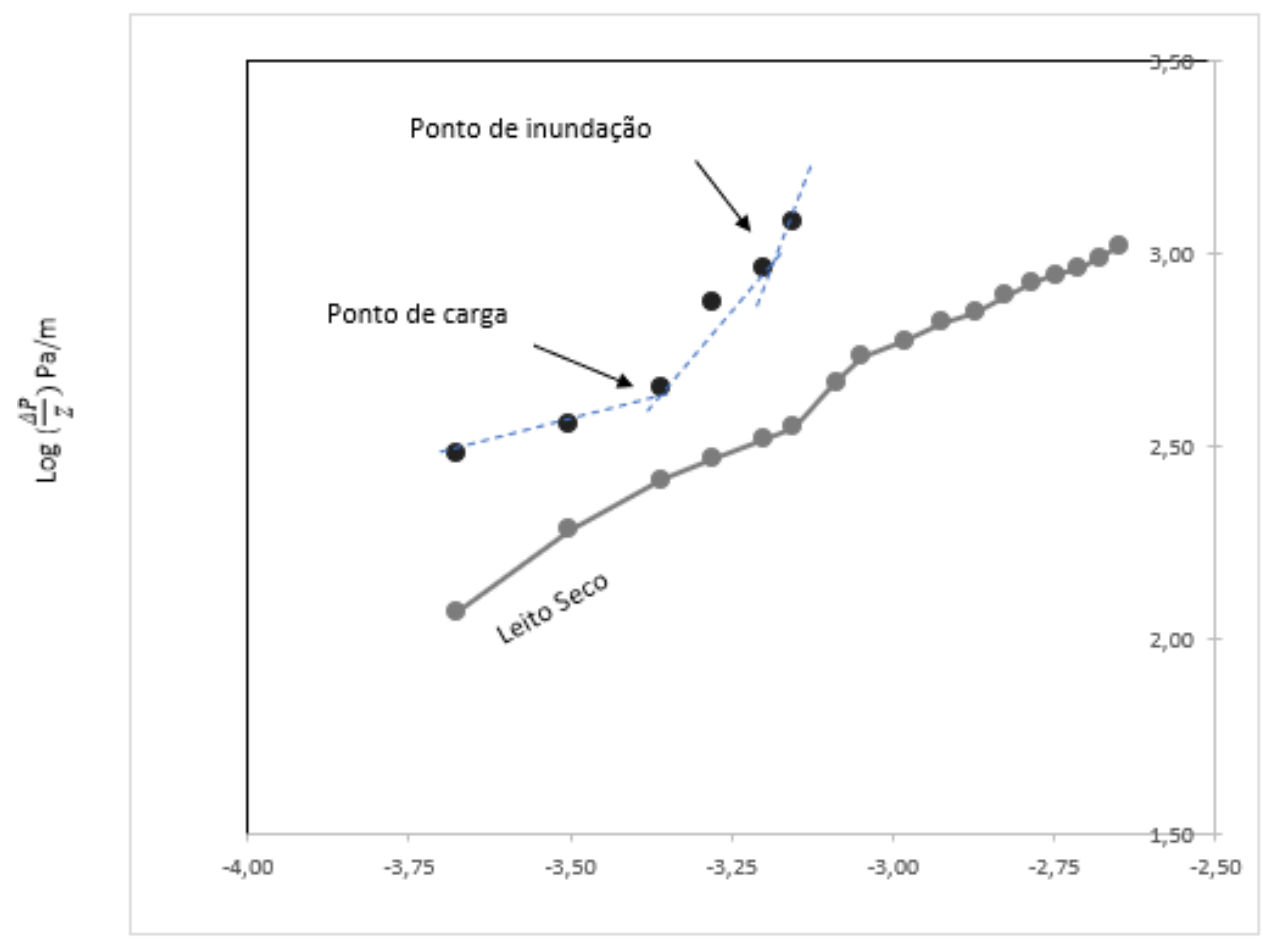

$\log ($ Uar $)\left(\mathrm{kmol} / \mathrm{m}^{2} \mathrm{~s}\right)$

Fonte: Autores. 
Figura 11: Variação da queda de pressão com fluxo de ar molar ( $\left.\mathrm{G}_{\text {água }}=1,41 \mathrm{~L} / \mathrm{min}\right)$.

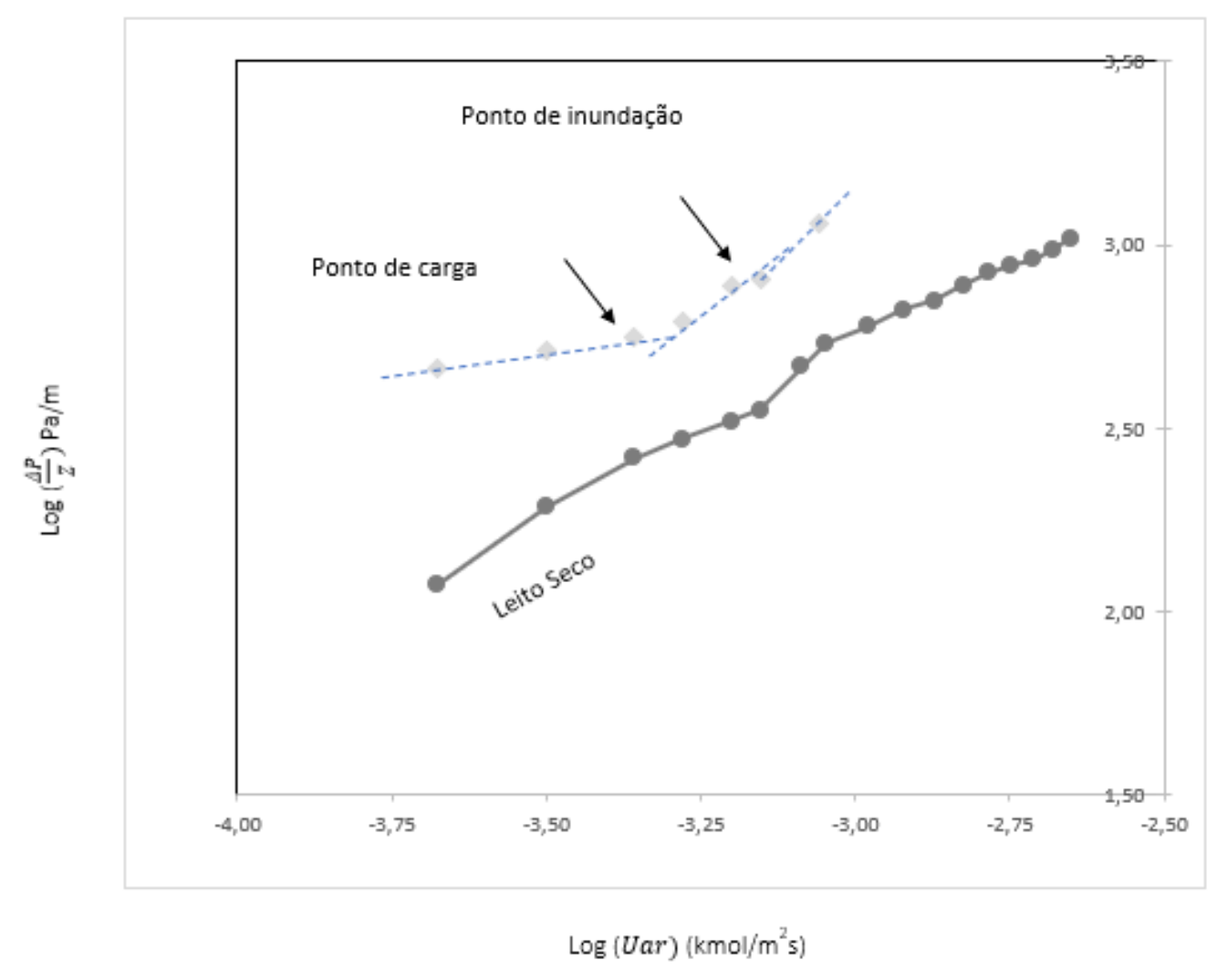

Fonte: Autores.

Analisando-se os 5 gráficos verifica-se primeiramente que é perfeitamente possível se determinar os pontos de inundação e de carga da coluna também observando-se o comportamento das curvas obtidas, através do modelo de Bianchini (2018). De acordo com os valores obtidos dos gráficos, as vazões carga e de inundação encontradas são descritas na Tabela 3.

Tabela 3: Vazões e quedas de pressão para os pontos de carga e de inundação

\begin{tabular}{cccccc}
\hline & Pontos de Carga & \multicolumn{3}{c}{ Pontos de Inundação } \\
\hline \hline $\begin{array}{c}\mathbf{G}_{\text {ar }} \\
(\mathbf{L} / \mathbf{m i n})\end{array}$ & $\mathbf{G}$ água & $\Delta \mathbf{P} / \mathbf{Z}$ & $\mathbf{G}_{\text {ar }}$ & $\mathbf{G}_{\text {água }}$ & $\Delta \mathbf{P} / \mathbf{Z}$ \\
& $(\mathbf{L} / \mathbf{m i n})$ & $(\mathbf{P a} / \mathbf{m})$ & $(\mathbf{L} / \mathbf{m i n})$ & $(\mathbf{L} / \mathbf{m i n})$ & $(\mathbf{P a} / \mathbf{m})$ \\
\hline \hline & 0,72 & 558,5 & & 0,72 & 843,9 \\
& 0,86 & 508,8 & & 0,86 & 831,5 \\
3 & 1,13 & 831,5 & 4 & 1,13 & 1154,1 \\
& 1,27 & 558,5 & & 1,27 & 1203,8 \\
& 1,41 & 769,4 & & 1,41 & 1141,7 \\
\hline
\end{tabular}

Fonte: Autores.

Conforme verificado nos dados apresentados na Tabela 3 observa-se primeiramente que todos os pontos encontrados foram para vazões de gás de 3,0L/min para os pontos de carga e de 4,0 L/min para os de inundação. Logo, identificados os pontos de carga e de inundação nos 5 diagramas pode-se construir um gráfico com os valores de $\Delta \mathrm{P}$ em função da vazão de água encontrados, gerando assim duas curvas distintas, uma para os pontos de carga e outra para os pontos de inundação, conforme mostrado no gráfico da Figura 12. 
Figura 12: As curvas de carga e de inundação.

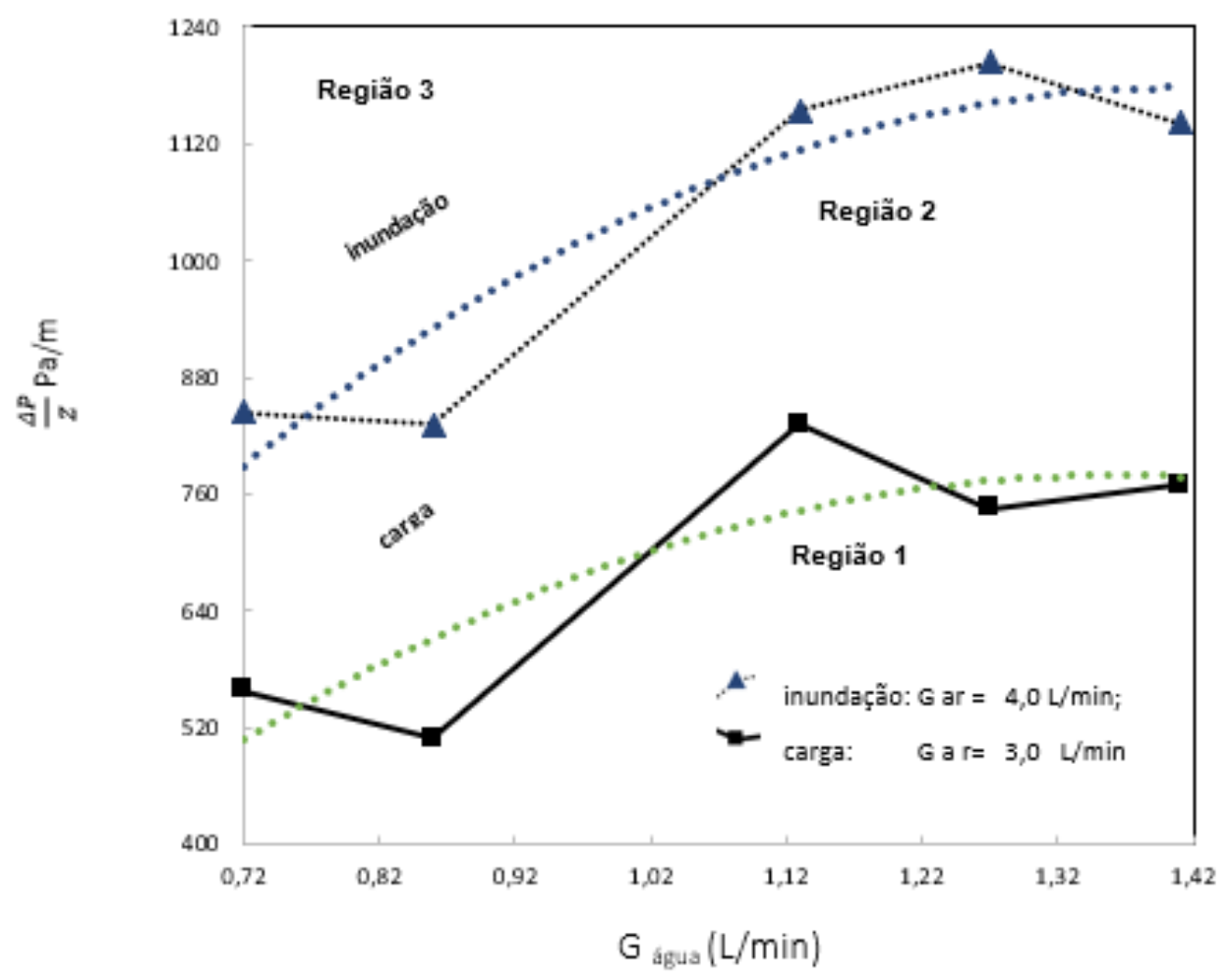

Fonte: Autores.

No gráfico da Figura 12 são formadas três regiões de operação da coluna. A região 1, localizada abaixo da linha de carga, a região 2, na faixa situada entre a linha de carga e a linha de inundação e a região 3, situada acima da curva de inundação. Ou seja, abaixo da linha de carga as duas fases se contatam por todo o comprimento da coluna. Na região 2 inicia-se o processo em que a fase gasosa começa a impedir a descida da corrente líquida. E na região 3, acima da curva de inundação, quando o acontece o arraste do líquido pela fase gasosa no topo da coluna.

Diante dos resultados obtidos dos experimentos realizados no presente trabalho pode-se concluir primeiramente da importância da determinação das faixas de carga e de inundação em uma coluna de recheio. Com estas faixas pode-se evitar a ocorrência do arraste de líquido pelo topo da coluna. A determinação do ponto crítico obtido também irá identificar o ponto em que se inicia a estabilização na queda de pressão na operação da torre.

Analisando-se o comportamento das três regiões, conclui-se que região 1 é a mais indicada para a operação das absorvedoras, já que nela as vazões, de líquido e de gás, escoam continuamente por todo o comprimento da coluna, favorecendo assim o processo de transferência de massa entre as fases. Nas operações com vazões situadas na região 2, geralmente acontece acúmulo de líquido na coluna, devido a ter-se iniciado o processo de impedimento do escoamento da corrente líquida pela gasosa. Na região 3, ou situada acima da curva de inundação, é quando acontece o arraste de líquido pela corrente gasosa e, portanto, a região onde não se deve operar a coluna.

\section{Lista de símbolos}

Gágua Vazão de Água (L/min)

$\mathrm{G}_{\mathrm{ar}}$ Vazão de Ar (L/min)

$\Delta \mathrm{P}$ Queda de Pressão 
$\mathrm{Z} \quad$ Comprimento da coluna (m)

$\mathrm{U}_{\mathrm{ar}} \quad$ Vazão de $\operatorname{ar}\left(\mathrm{Kmol} / \mathrm{m}^{2} \mathrm{~s}\right)$

\section{Conclusões}

Diante dos dados apresentados no presente trabalho pode-se concluir que vários aspectos foram determinados visando a eficiência na operação da absorvedora.

Primeiramente foi constatado o aumento da queda de pressão com as vazões, tanto de gás como de líquido, conforme observado no gráfico da Figura 5. Este estudo foi ampliado através do gráfico da Figura 6 quando foi determinada o ponto crítico, de onde se inicia a faixa de estabilidade da coluna.

Vazões de carga e de inundação foram determinadas com o modelo de Bianchini (2018), através das inclinações das linhas de operação formadas. No gráfico da Figura 12 foram obtidas as curvas de carga e de inundação onde são identificas três regiões de operação da torre, onde em cada região são apresentadas condições específicas de operação.

Finalmente, com o presente estudo espera-se que se possa operar torres de recheio de forma mais eficiente e prática, através do ajuste das vazões de líquido e de gás.

Após a realização do estudo hidrodinâmico da coluna nesse trabalho, torna-se possível a utilização do aparato experimental para a realização de testes de transferência de massa na coluna; bem como a realização de outros estudos hidrodinâmicos, variando a altura do recheio da coluna, como o tipo de recheio, suas características, assim quanto suas dimensões; Interessante também realizar os procedimentos com outros tipos de substâncias para identificar a variabilidade dos dados junto a essa mudança.

\section{Agradecimentos}

Este trabalho teve apoio da (CAPES / Brasil) para obtenção do título de Mestre de João Carlos Ferreira Lima.

\section{Referências}

Bernardes, A. P. D. \& Góis, L. M. N. (2020). Evaluation of efficiency and mass transfer in a pulsed packed extraction column. Research, Society and Development, 9(2), e132922185. 10.33448/rsd-v9i2.2185.

Bianchini, R. H. L. (2018). Estudo comparativo da absorção e dessorção de dioxido de Carbono em Colunas para Solução de Aminas: Monoetileno amina e Monodietil Amina Piperazina. Dissertação de Mestrado- Universidade de São Paulo.

Billet, R. \& Mackowiak, J. J. (1984). Fette Seifen Anstrichminel. 86, 342-358.

Cajueiro, R. L. P. (2013). Manual para elaboração de trabalhos acadêmicos: guia prático do estudante/Roberta Liana Pimentel Cajueiro. (2a ed.), Petrópolis, RJ.

Caldas, J. N. \& Lacerda, A. I., (2003). Internos de torres: pratos \& recheios. Ed. UERJ, 466 .

Costa, J. C. da; Góis, L. M. N. de; Mattedi S. (2020). Holdup and characteristic velocity in a pulsed packed extraction column. Research, Society and Development, 9(8), e674982543. 10.33448/rsd-v9i8.2543.

Darake, S., Rahimi, A., Hatamipour, M. S. \& Hamzeloui, P., (2014). SO $\mathrm{O}_{2}$ removal by seawater in a packed-bed tower: experimental study and mathematical modeling. Sep. Sci. Technol. 49, 988-998. http://dx.doi.org/10.1080/01496395.2013.872660.

Ergun, S. (1952). Fluid flow through packed columns. Chem. Eng. Prog. 48.

Flagiello, D., Di Natale, F., Carotenuto, C., Erto, A. \& Lancia, A. (2018a). Seawater desulphurization of simulated flue gas in spray and packed columns: an experimental and modelling comparison. Chem. Eng. Trans. 69, http://dx.doi.org/10.3303/CET1869134.

Flagiello, D., Erto, A., Lancia, A. \& Di Natale, F. (2018b). Experimental and modelling analysis of seawater scrubbers for sulphur dioxide removal from fluegas. Fuel 214, 254-263. http://dx.doi.org/10.1016/j.fuel.2017.10.098.

Flagiello, D., Parisi, A., Lancia, A., Carotenuto, C., Erto, A. \& Di Natale, F.(2019). Seawater desulphurization scrubbing in spray and packed columns for a 4.35 MW marine diesel engine. Chem. Eng. Res. Des. 148, 56-67, http://dx.doi.org/10.1016/j.cherd.2019.05.057 
Research, Society and Development, v. 10, n. 3, e29410312369, 2021

(CC BY 4.0) | ISSN 2525-3409 | DOI: http://dx.doi.org/10.33448/rsd-v10i3.12369

Graff, K., (1985). Oil \& Gas Journal.

Guillerm, M., Couvert, A., Amrane,A., Norrant,E. Lesage, N. \& Doumont, E. (2016). Absorption of toluene in silicone oil: Effect of the solvent viscosity on hydrodynamics and mass transfer - Chemical Engineering Research and Design Volume 109, 32-40.

Heyouni, A., Roustan, M. \& Do-quang, Z. (2002). Hydrodynamics and mass transfer in gas-liquid flow through static mixers. Chemical Engineering Science, $57,3325-3333$.

Iliuta, I. \& Larachi, F. (2019). Modeling and simulations of NOx and $\mathrm{SO}_{2}$ seawater. Catal. Artic. 489, http://dx.doi.org/10.3390/catal9060489.

Koche, J. C. (2011). Fundamentos de metodologia científica. Petrópolis: Ed Vozes. http://www.brunovivas.com/wpcontent /uploads/sites/10/2018/07/K\%C3\%B6che-Jos\%C3\%A9-Carlos0D0AFundamentos-de-metodologia-cient\%C3\%ADfica-_-teoria-da0D0Aci\%C3\%AAncia-einicia\% $\%$ \% A7\% $3 \%$ A3o-\%C3\%A0-pesquisa.pdf.

Leva, M. (1953). Tower Packings and Packed tower Design. (2a ed.), The United States Stoneware Copany.

Liu,S. Hu, R., Zhao, J., Brüggemann, N., Bol, R. Cai, G., Lin, S. \& Shaaban, M. (2014). Flooding effects on soil phenol oxidase activity and phenol release during rice straw decomposition - Journal of plant nutrition and soil science. https://doi-org.ez10.periodicos.capes.gov.br/10.1002/jpln.201300356.

Nobrega, G.A.S. (2007). Estudo de uma coluna de absorção recheada para desidratação do gás natural utilizando microemulsão como absorvente - Tese de Doutorado, Programa de Pós- Graduação em Engenharia Química - Universidade Federal do Rio Grande do Norte.

Niranjan, K. (1983). Chem. Eng., 90, 67.

Pereira, A. S., Shitsuka D. M., Parreira, F. J. \& Shitsuka, R. (2018). Metodologia da pesquisa científica. UFSM. https://www.ufsm.br/app/uploads/sit es/358/2019/02/Metodologia-da-Pesquisa-Cientifica_final.pdf

Prahl, W. H. (1970). Liquid Density Distorts Packed Column Correlation. Chemical Engineering, 77 (24), $109-112$.

Schultes, M., Brauer, J., Chen, P. \& Doong, S. (2018.) Marinization of mass transfer columns for FLNG applications. Chem. Eng. Trans. 69, 301-306. http://dx.doi.org/10.3303/CET1869051.

Treybal, R. E, (1980). Mass-Transfer Operation, Third Edition. McGraw-Hill Book Company. 